\title{
Wave Power Potential of Sri Lanka
}

\section{H. Karunarathna, P. Maduwantha, H. Ratnasooriya, K. De Silva and B. Kamranzad}

\begin{abstract}
The paper assesses wave power potential around Sri Lanka, using a numerically simulated, 25 year long wave dataset. The results reveal that the south-west to south-east coasts of Sri Lanka have 12-15 kW/m of annual average wave power, which is suitable for offshore, large-scale wave energy harvesting. Further studies with high resolution computational modelling supported by in-situ wave measurements may be necessary to evaluate the nearshore wave resource, which will be appropriate for small scale, localised energy capture. As the coastline of Sri Lanka is prone to coastal erosion and has diverse and dynamic eco-sedimentary systems, thorough environmental evaluations to investigate the impacts of wave energy uptake will be essential before embarking on any wave energy project.
\end{abstract}

Keywords: Wave power, Ocean wave, Computational modelling, Environmental impact

\section{Introduction}

Exploitation of renewable energy resources to replace fossil fuels has become a global priority to alleviate climate change impacts. Among numerous forms of renewable energy sources, marine energy is considered as a viable form of energy for countries surrounded by coastal seas and oceans. The main forms of marine energy being considered are tidal (either tidal stream or tidal range) energy and wave energy. The feasibility of wave energy as a contender to the renewable energy mix has been investigated world-wide. An extensive review of literature on wave energy resource assessments can be found in [4].

Sri Lanka is surrounded by the northern Indian Ocean. Long-distance swell waves approaching from the southern Indian Ocean reach the west to south-east coastline of Sri Lanka all-yearround. Meanwhile, the two tropical monsoon systems operating in the Indian Ocean generate highly energetic sea waves. As a result, the south and the west coasts of Sri Lanka experience the combined effect of swell and sea waves during the south-west monsoon from May to September while the north and east coasts of Sri Lanka experience energetic seas during the north-east monsoon from October to December. The consistent swell wave approach and the energetic seas generated by local wind waves make Sri Lanka an ideal location for wave energy harvesting.

Numerous forms of technology are available for generating wave energy. Wave energy devices, which can be either floating or fixed to seabed, are classified based on the principle of wave energy conversion. An attenuator device floats on the sea surface and captures energy from the relative motion between the device and the propagating waves; a point absorber device captures wave energy from all directions through its vertical movement near the sea surface and converts it into electricity; an oscillating water column is a partially submerged structure in which waves cause rise and fall of the water column inside the structure. This allows the trapped air between the water surface and the roof of the structure to escape to the atmosphere through a turbine which generates electricity, and a submerged pressure differential device, which is attached to the seabed, generates electricity from the pressure difference generated by the rise and fall of the sea surface by passing waves as given in http://www.emec.org.uk/marine energy/w ave-devices/ [13].

While some of the above technologies are suitable for deep water or intermediate water wave energy harvesting (e.g. attenuator disks and point absorbers), others are suitable mainly for shallow water applications (e.g. oscillating water column and submerged pressure differential devices).

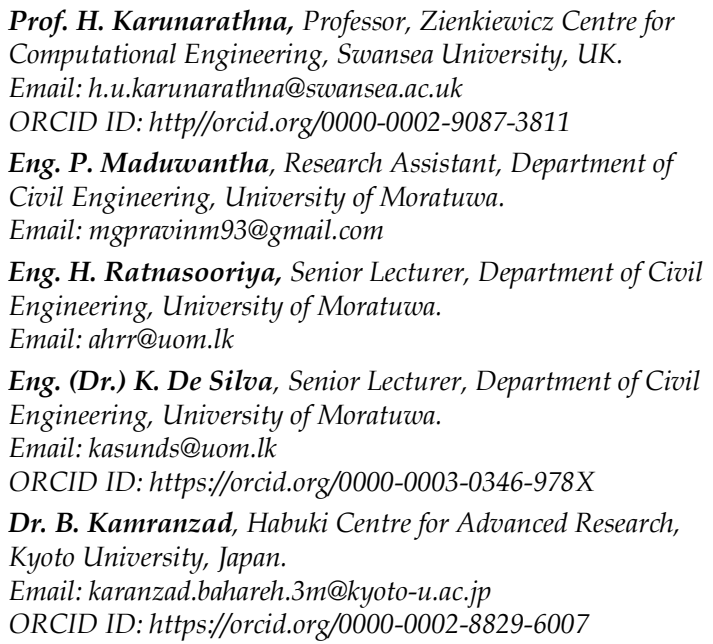


In this broad-scale study, the wave power potential of Sri Lanka was assessed using a numerically simulated 25 year-long wave data set between 1979 and 2003. The primary aim of this study was to investigate the spatiotemporal variability of the available wave resource and to identify power hotspots around the coast. The challenges of wave energy generation in the Sri Lankan context and the potential environmental implications of wave energy harvesting were also identified by the study.

\section{Models and Methods}

A computational wave model was established to simulate high-resolution wave climate around Sri Lanka (KU_SLK) using a $3^{\text {rd }}$ generation spectral wave simulation software 'Simulating WAves Nearshore (SWAN)', (Booji et al., 1999 [1]). The spatial resolution of the model was $0.05^{\circ}$. KU_SLK model was forced by wave simulations from an Indian reginal-scale wave model (KU_IND), which has been nested to a large-scale Indian Ocean wave model KU_IO (Kamranzad and Mori, 2019 [5]). KU_SLK model domain covers the geographic region of $\left(5-11^{\circ} \mathrm{N}: 79 \cdot 5-83.5 \mathrm{E}^{\circ}\right)$. The model consists of wave frequencies between 0.03 and $1.0 \mathrm{~Hz}$. The cascade of computational model domains is shown in Figure 1. The wind input which drives the wave climate in the KU_IO model was taken from the Japan Meteorological Agency super high-resolution global climate model MRI-AGCM 3.2 S (Kamranzad and Mori, 2019 [5]). The spatial and temporal resolutions of the input wind field were $30 \mathrm{~km}$ and $1 \mathrm{hr}$, respectively.

Twenty-five years' worth wave simulations from 1979 to 2003, which is representative of the wave climate under the current global climate, was carried out using the KU_SLR model. The model has a uniform grid with spatial resolution of $0.05^{\circ} \times 0.05^{\circ}$ and provides the spectral wave height $\left(H_{\mathrm{m} 0}\right)$ derived from the zeroth moment of the wave frequency spectrum (which closely resembles the significant wave height $H_{\mathrm{s}}$ in the time domain); first spectral wave period $\left(T_{\mathrm{m} 01}\right)$; and the spectral frequency density function $S(f)$ (Equations (1) to (3)) at all model grid nodes.

$$
\begin{aligned}
& H_{m o}=4 \sqrt{m_{0}} \\
& T_{m 01}=\sqrt{\frac{m_{0}}{m_{1}}} \\
& m_{k(k=0,1,2 \ldots, n)}=\int_{f=0}^{\infty} f^{k} S(f) d f
\end{aligned}
$$

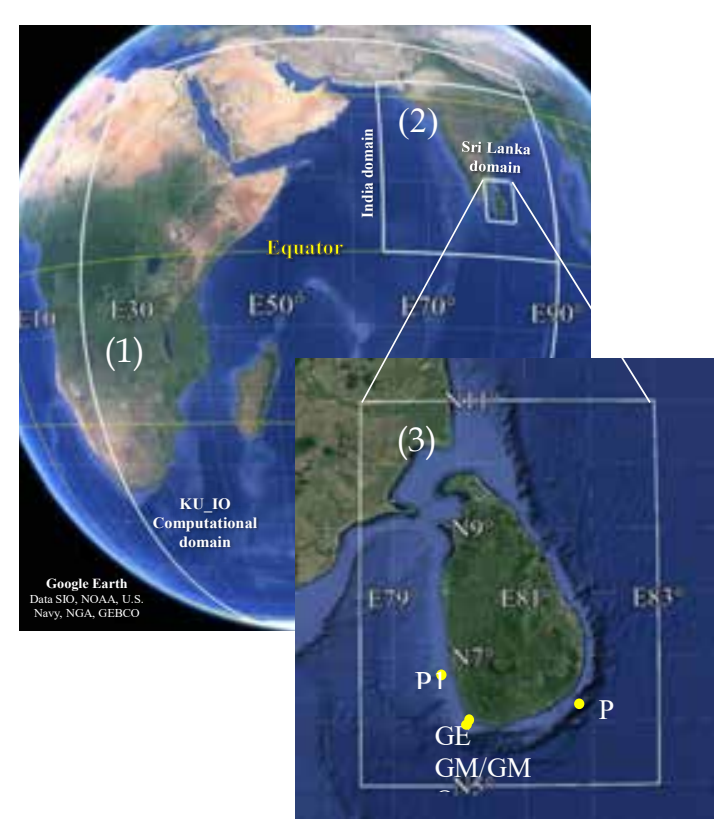

Figure 1 - Indian Ocean KU_IO (1), India Regional (KU_IND) (2) and Sri Lanka (KU_SLK) (3) Wave Model Domains used for Wave Simulations for Sri Lanka (Note KU_SLR wave model validation points are marked in yellow circles [GMO- $5.931 \mathrm{~N}$ 80.232E; GE- 6N:80.25E; GM- 5.93N:80.23E; P1$6.750 \mathrm{~N}, 79.750 \mathrm{E}$; P2- 6.250N, 81.750E])

The KU-SLR model was validated against two datasets: (i) Wave data collected offshore of Galle $\left(5.93^{\circ} \mathrm{N}: 80.23 \mathrm{E}^{\circ}\right)$, over a period of 3.5 years from 1989 to 1992 (GM - Figure 1). The data were collected by the Coast Conservation Department of Sri Lanka (CCD), in association with the German Agency for Technical Corporation (GTZ). A DATAWELL B.V. directional wave buoy had been used to collect wave data for 30 minute duration, every three hours (Sheffer et al., 1994 [12]); and (ii) Interim Global Atmospheric Reanalysis wave data (ERA-Interim) produced by the European Centre for Medium-range Weather Forecasts (ECMWF) (https://apps.ecmwf.int/datasets/ [14]) at six hourly intervals. The simulated wave climate was compared with the ERA-Interim wave data at three locations around the coast of Sri Lanka (GE-6.00N, 80.25E; P1- 6.75N, 79.75E; and P2 $-6.25 \mathrm{~N}, 81.75 \mathrm{E}$ ) (Figure 1).

A comparison of simulated GMO, measured GM and ERA-Interim GE wave heights off the coast of Galle [Figure 1] over a period of three years is shown in Figure 2. Although the model has not been able to capture some extreme wave heights that occurred during this period, it correctly reproduced the day-to-day wave heights and seasonal fluctuations. An extensive validation of the model can be found in Karunarathna et al., 2020a [6]. 


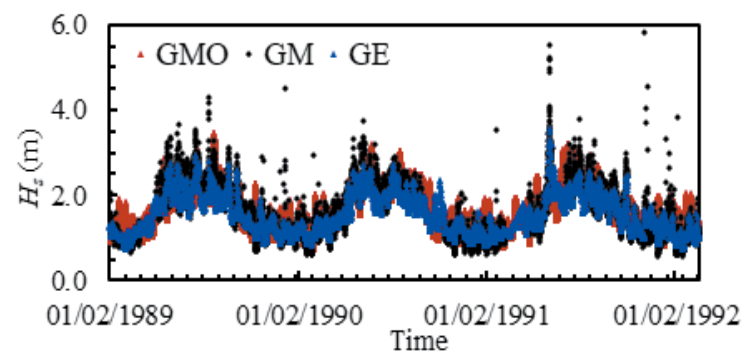

Figure 2 - A Comparison of Simulated, Measured and ERA Interim Wave Height Time Series [modelled - red, ERA-Interim Reanalysis - blue and measured - black] (Karunarathna et al., 2020b [7])

\section{Results and Discussion}

The simulations of wave climate from the validated KU-SLR model were used to assess the available wave power around Sri Lanka under the current climate. The 25-year average wave power around Sri Lanka is shown in Figure 3 . The wave power $P$ was calculated using Equation (4) (MARINET, 2015 [9]), which is based on the Linear Wave Theory.

$P=0.49 H_{s}^{2} T_{m-10}$

where $T_{\mathrm{m}-10}$ is the energy period given by $T_{m-10}=\frac{m_{-1}}{m_{0}}$ (Pitt, 2009 [10]), in which $m_{-1}$ is the first negative spectral moment of the wave frequency spectrum.

The west to south-east coast of Sri Lanka has the highest average wave power, due to the superposition of the long-distance swell waves approaching from the southern Indian Ocean with the local monsoonal sea waves. According to the model results, the average power varied between $12-16 \mathrm{~kW} / \mathrm{m}$ along the continental shelf margin. Comparatively, the north and the east coasts of Sri Lanka show significantly less wave power, varying between $2-4 \mathrm{~kW} / \mathrm{m}$. As the consistent swell waves are found to be the most favourable for wave energy harvesting (Fairley et al., 2020 [2]), the attention was focussed on the stretch of coast from the northwest to the south-east for the analyses and discussions presented herein.

For detailed analysis of wave power potential, ten offshore locations (M1 to M10) were selected along the margin of the north-west to south-east continental shelf of Sri Lanka, details of which are given in Figure 4 and Table 1. All selected locations satisfied either the 'intermediate water depth' or 'deep water' condition with respect to incoming waves and therefore, qualify to apply Equation (4) to establish available wave power.

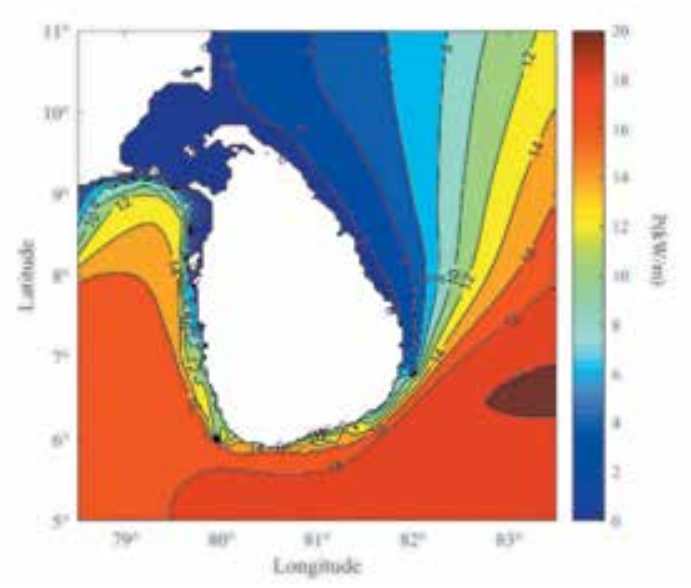

Figure 3 - The Average Wave Power Around Sri Lanka

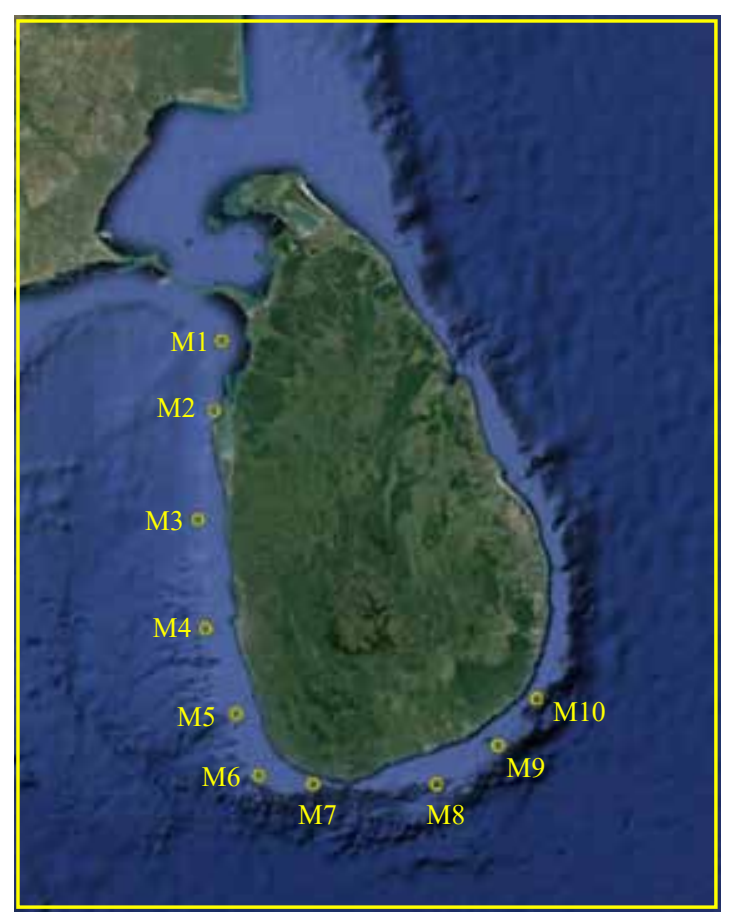

Figure 4 - Locations (M1 to M10) used for a Detailed Analysis of Wave Power Around the North-West to South-East Coast of Sri Lanka

The locations M1 to M10 are subjected to a variety of different wave conditions. The wave climate at M1 and M2 is fetch-limited and characterised primarily by the locally generated wind waves. M3 to M8 are exposed to all-year southerly swell wave approach. The swell is significantly modulated by the energetic sea waves generated during the south-west tropical monsoon between May and September. M9 has some influence from the south-west monsoongenerated sea waves but swell waves are dominant. Wave climate in M10 is also 
governed by the southerly swell waves while having some effects of the north-east tropical monsoon.

Table 1 - Geo-Coordinates and the Water Depth of the Locations M1 to M10 Around the Coastline of Sri Lanka from North-West to South-East

\begin{tabular}{|c|c|c|}
\hline $\begin{array}{l}\text { Location } \\
\text { (Figure 4) }\end{array}$ & Geo-coordinates & $\begin{array}{c}\text { Water } \\
\text { depth }(\mathrm{m})\end{array}$ \\
\hline M1 & $8^{\circ} 45^{\prime} \mathrm{N} \quad 79^{\circ} 45^{\prime} \mathrm{E}$ & 18 \\
\hline M2 & $8^{\circ} 18^{\prime} \mathrm{N} \quad 79^{\circ} 42^{\prime} \mathrm{E}$ & 30 \\
\hline M3 & $7^{\circ} 36^{\prime} \mathrm{N} \quad 79^{\circ} 36^{\prime} \mathrm{E}$ & 100 \\
\hline M4 & $6^{\circ} 54^{\prime} \mathrm{N} \quad 79^{\circ} 39^{\prime} \mathrm{E}$ & 45 \\
\hline M5 & $6^{\circ} 21^{\prime} \mathrm{N} \quad 79^{\circ} 51^{\prime} \mathrm{E}$ & 63 \\
\hline M6 & $5^{\circ} 57^{\prime} \mathrm{N} \quad 80^{\circ} 00^{\prime} \mathrm{E}$ & 73 \\
\hline M7 & $5^{\circ} 54^{\prime} \mathrm{N} \quad 80^{\circ} 21^{\prime} \mathrm{E}$ & 58 \\
\hline M8 & $5^{\circ} 54^{\prime} \mathrm{N} \quad 81^{\circ} 09^{\prime} \mathrm{E}$ & 60 \\
\hline M9 & $6^{\circ} 09^{\prime} \mathrm{N} \quad 81^{\circ} 33^{\prime} \mathrm{E}$ & 58 \\
\hline M10 & $6^{\circ} 27^{\prime} \mathrm{N} \quad 81^{\circ} 48^{\prime} \mathrm{E}$ & 48 \\
\hline
\end{tabular}

In Figure 5, the average annual wave power potential at M1 to M10 is given for the 25-year simulation period. Although a small interannual variability is apparent at most locations, which may be potentially due to local climatic variabilities, annual average wave power at all locations is stable and consistent throughout the simulation period. However, a significant spatial variability can be seen.

The locations M1 to M3 have annual average offshore wave power potential of less than $7 \mathrm{~kW} / \mathrm{m}$ in any given year. In contrast, M6 to M8 have over $15 \mathrm{~kW} / \mathrm{m}$ of annual average power potential in most years. The wave power at M4, M5, M9 and M10 varies between $10-15 \mathrm{~kW} / \mathrm{m}$. Although the annual average wave power potential in Sri Lanka is not as large as in some high-latitude regions (e.g. Reguero et al., 2015 [11]), the consistency and stability of the resource over a long period of time is favourable for energy harvesting.

\section{Technical Challenges and Environmental Implications}

Although Sri Lanka has a stable and consistent wave power resource, there are technical and environmental challenges that need to be assessed in detail. Wave energy sector is currently at a stage where numerous prototype devices have been designed and developed. However, to improve the reliability and performance of devices, optimal energy harvesting and making the technology costeffective, further research is needed to identify the best device for a given wave climate.

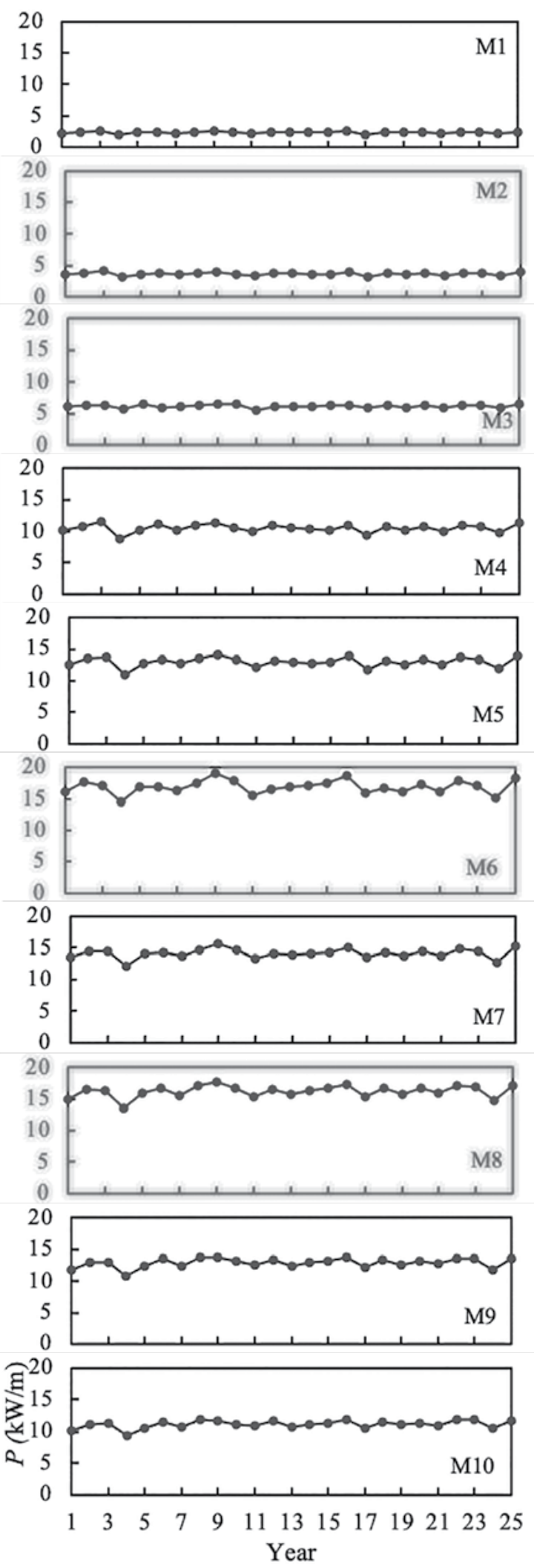

Figure 5 - Annual Average Wave Power at M1 to M10 (1 in $x$-axis corresponds to year 1979 and 25 to year 2003)

Wave climate in the southern Sri Lanka, where the annual average resource is larger than $15 \mathrm{~kW} / \mathrm{m}$, is suitable for large-scale, deepwater wave energy installations. Most other locations are excellent candidates for small to medium 
scale developments. Further high-resolution computational modelling studies supported by nearshore wave measurements for detailed analysis of the nearshore wave climate are essential for spatial planning and device selection for nearshore wave energy projects.

Numerous researches have been published on the effect of the potential to combine wave energy harvesting with coastal defence against highly energetic seas (e.g. Manasseh et al., 2017 [8]; Felix et al., 2019 [3]). This will be a useful scenario for Sri Lanka where a number of locations along the coastline is currently eroding and requires high level of defence against coastal erosion.

Although environmental implications of offshore wave energy harvesting may be less significant, nearshore energy harvesting may have multiple impacts. Modified nearshore wave climate due to energy extraction may alter the nearshore hydrodynamics and littoral sediment transport regime. This may have the potential to negatively or positively impact nearshore morphodynamics, coastal ecosystems such as coral reefs, sea grass beds and mangroves, and marine fish and other species breeding and movement. The key to effectively minimise any negative impact is the deployment of thorough environmental assessments and careful spatial planning and adaptation of sustainable construction technologies and impact mitigation measures.

\section{Conclusions}

In this paper, the offshore wave power potential of Sri Lanka was assessed, using a set of 25-year long wave simulations derived by a computational wave model. Based on the results of the assessment, the following conclusions are made:

- $\quad$ The west and the south coasts of Sri Lanka have a significant, stable and consistent wave power potential, comparable with wave power hotspots worldwide.

- Further high-resolution computational modelling aided by wave measurements will be required to identify localised power hotspots, which is essential for spatial planning, power optimisation and device selection.

- Environmental implications of wave energy harvesting need to be evaluated before embarking on any wave energy project.
- It is worth considering the potential to combine energy harvesting with coastal protection in any nearshore wave energy project.

\section{Acknowledgement}

The authors acknowledge the financial support provided by Swansea University, UK through the Global Challenge Research Fund project 'Wave energy resource characterisation for Sri Lanka in a changing ocean climate'. The study was partially supported by the Senate Research Committee Grant SRC/ST/2019/55 provided by the University of Moratuwa. Dr. B. Kamranzad acknowledges Japan Meteorological Agency for providing the atmospheric model outputs to run the wave models and who was supported by the Hakubi Center for Advanced Research at Kyoto University, Japan and JSPS Grants-in-Aid for Scientific Research (KAKENHI) supported by the Ministry of Education, Culture, Sports, Science, and Technology-Japan (MEXT). Dr. Nalin Wickramanayake (Open University of Sri Lanka) and Mr. Sujeewa Ranawaka (Coast Conservation and Coastal Resource Management Department) are greatly acknowledged for sharing wave data and providing other useful information.

\section{References}

1. Booji, N., Ris, R. C. and Holthuijsen, L. H., “A Third-generation Wave Model for Coastal Regions, Part 1. Model Description and Validation", J. Geophys., 1999, Res. 104 (C4), pp. 7649-7666.

2. Fairley, I., Louise, M., Robertson, B., Hemer, M., Masters, I., Caraballo, J. H., Karunarathna, H. and Reeve, D. E., "A Classification System for Global Wave Energy Resources Based on Multivariate Clustering", Applied Energy, 2020, 262(114515).

3. Felix, A., Hernandez-Fontes, J. V., Lithgow, D., Mendoza, E., Posada, G., Ring, M. and Silva, R., “Wave Energy in Tropical Regions: Deployment Challenges, Environmental and Social Perspectives", J. Mar. Sci. Eng., 2019, 2 (219).

4. Guillou, N., Lavidas, G. and Chapalain, G., "Wave Energy Resource Assessment For Exploitation", J. Mar. Sci. Eng., 2020, 8(705).

5. Kamranzad, B. and Mori, N., "Future Wind and Wave Climate Projections in the Indian Ocean Based on a Super-High-Resolution MRIAGCM3.2S Model Projection", Climate Dynamics, 2019, 53, pp 1-20. 
6. Karunarathna, H., Maduwantha, P., Kamranzad, B., Rathnasooriya, H. and De Silva, K., "Evaluation of Spatio-Temporal Variability of Ocean Wave Power Resource Around Sri Lanka", Energy, 2020a, 200.

7. Karunarathna, H., Maduwantha, P., Kamranzad, B., Rathnasooriya, H. and De Silva, K., "Impacts of Global Climate Change on the Future Ocean Wave Power Potential: A Case Study From the Indian Ocean", Energies, 2020b, 13 (3028).

8. Manasseh, R., Sannasiraj, S. A., McInnes, K., Sundar, V. and Jalihal, P., "Integration of Wave and Other Marine Energy Sources with the Need of Coastal Societies", Ocean and Climate Systems, 2017, 8(1), pp. 19-36.

9. MARINET, “A Report on 'Standards for Wave Data Analysis, Archival and Presentation, Cork, Ireland", 2015.

10. Pitt, E., “Assessment of Wave Energy Resource, Marine Renewable Energy Guides, European Marine Energy Centre Limited, 2009.

11. Reguero, B. G., Losada, I.J. and Méndez, F. J., "Global Wave Power Resource and its Seasonal, Interannual and long-term Variability", App. Energy, 2015, 148, pp. 366-380.

12. Sheffer, H. J., Fernando, K. R. M. D and Fittschen, T., "CCD-GTZ Directional Wave Climate Study South-West Coast of Sri Lanka", Report on the wave measurements off Galle, 1994.

13. http://www.emec.org.uk/marine-energy/wavedevices/, Visited, 2020/07/12.

14. https://apps.ecmwf.int/datasets/, Visited, 2020/07/12. 